\title{
Calculation of Supercooled Liquid Range and Estimation of Glass-Forming Ability of Metallic Glasses using the Vogel-Fulcher-Tammann Equation
}

\author{
Akira Takeuchi and Akihisa Inoue \\ Institute for Materials Research, Tohoku University, Sendai 980-8577, Japan
}

\begin{abstract}
The supercooled liquid range $\left(\Delta T_{\mathrm{x}}\right)$ was calculated on the basis of the free volume theory proposed by Beukel and Sietsma. A differential equation which expresses the change in free volume from a non-equilibrium to an equilibrium state has been analyzed numerically for $\mathrm{Ni}$, metallic glasses and $\mathrm{SiO}_{2}$ systems. The Vogel-Fulcher-Tammann (VFT) equation for viscosity was used to define the equilibrium free volume. The maximum $\Delta T_{\mathrm{x}}$ was calculated as $56 \mathrm{~K}$ for the $\mathrm{SiO}_{2}$ system. The calculated $\Delta T_{\mathrm{x}}$ was approximately six times smaller than the experimental result. The calculation results of the $\log R_{\mathrm{c}}\left(R_{\mathrm{c}}\right.$ : critical cooling rate for glass formation)- $\Delta T_{\mathrm{x}}$ diagram shows a tendency similar to the experimental result; $\log R_{\mathrm{c}}$ decreases linearly with increasing $\Delta T_{\mathrm{x}}$. An approximate solution of the differential equation was also obtained with elementary functions. It was found that the glass transition temperature $\left(T_{\mathrm{g}}\right)$ and $\Delta T_{\mathrm{x}}$ can be obtained schematically in the free-volumetemperature diagram. All the factors expressing the glass-forming ability of the metallic glasses can be derived from the VFT parameters.
\end{abstract}

(Received November 26, 2001; Accepted March 18, 2002)

Keywords: supercooled liquid range, glass transition temperature, free volume, Vogel-Fulcher-Tammann equation, viscosity, metallic glass, glass-forming ability, specific heat

\section{Introduction}

Since the first successful preparation of an amorphous phase in an Au-Si system in 1960, ${ }^{1)}$ a great number of amorphous alloys have been found. Some of the amorphous alloys which exhibit the glass transition phenomena are classified as metallic glasses according to the scientific definition. Recently, a number of metallic glasses have been found in special multicomponent systems ${ }^{2)}$ in which the nucleation and growth reactions of a crystalline phase are suppressed. These metallic glasses exhibit similar unique characteristics to those found among the amorphous alloys in terms of their physical, chemical, mechanical, and magnetic properties. However, a significant difference has been discerned in their thermal properties. That is, the metallic glass, when subjected to continuous heating exhibits the glass transition temperature $\left(T_{\mathrm{g}}\right)$, and then transforms into a large supercooled liquid.

The glass-forming ability (GFA) is generally indicated by the minimum cooling rate to avoid the nucleation and growth of crystals during continuous cooling from the melted state. In fact, this parameter is also applicable to the amorphous alloys because both the amorphous alloys and metallic glasses vitrify into a non-crystalline state by the mechanism described above. Accordingly, the GFA has been practically estimated using the following three factors: ${ }^{2)}$ (1) reduced glass transition temperature $\left(T_{\mathrm{g}} / T_{\mathrm{m}}\right)$, (2) supercooled liquid range $\Delta T_{\mathrm{x}}$ (= $T_{\mathrm{x}}-T_{\mathrm{g}}$ ), and (3) critical cooling rate $\left(R_{\mathrm{c}}\right)$ for formation of the glassy phase. The first two factors are determined from the following three temperatures which are measured by thermal analysis, i.e., the glass transition temperature $\left(T_{\mathrm{g}}\right)$, melting temperature $\left(T_{\mathrm{m}}\right)$, and onset temperature of crystallization $\left(T_{\mathrm{x}}\right)$. On the basis of the experimental results, the dominant factors for GFA are summarized in the $R_{\mathrm{c}}-T_{\mathrm{g}} / T_{\mathrm{m}}$ and $R_{\mathrm{c}}-\Delta T_{\mathrm{x}}$ diagrams. ${ }^{2)}$ These diagrams indicate that the metallic glasses with high GFA have the following threshold values for the GFA factors: $R_{\mathrm{c}} \leq 10^{5} \mathrm{~K} / \mathrm{s}, T_{\mathrm{g}} / T_{\mathrm{m}} \geq 0.6$ and $\Delta T_{\mathrm{x}} \geq 50 \mathrm{~K}$.
In addition to the experimental studies on the GFA factors for metallic glasses, a number of theoretical studies have been carried out to evaluate the $R_{\mathrm{c}}{ }^{3-14)}$ and to clarify the relation between $R_{\mathrm{c}}$ and $T_{\mathrm{g}} / T_{\mathrm{m}} \cdot{ }^{4,6,13)}$ The GFA factors have been recently summarized ${ }^{15,16)}$ for typical metallic glasses by combining the theoretical $R_{\mathrm{c}}$ with the experimental results of $T_{\mathrm{g}} / T_{\mathrm{m}}$ and $\Delta T_{\mathrm{x}}$. To our knowledge, however, the relationship among all the GFA factors have not been analyzed theoretically in the framework of a general model.

We have thus started to establish the general models for analyzing the quantities of the metallic glasses from a theoretical point of view. As a result, we have succeeded in deriving a relationship corresponding to the experimental result of $R_{\mathrm{c}}-T_{\mathrm{g}} / T_{\mathrm{m}}$ from a time-transformation diagram ${ }^{17)}$ which expresses the crystallization of metallic glass. It should be noted that to calculate the transformation diagram only two necessary parameters are necessary: the Vogel-FulcherTammann (VFT) equation for viscosity and the melting temperature $\left(T_{\mathrm{m}}\right)$. It is also important to note that the factor $T_{0} / T_{\mathrm{m}}$ ( $T_{0}$ : ideal glass transition temperature) can be substituted for $T_{\mathrm{g}} / T_{\mathrm{m}}$ in order to avoid the difficulty in analyzing the $T_{\mathrm{g}}$ which varies with the heating rate. This substitution of the factor implies the conversion of a variable from a kinetic to a thermodynamic transformation temperature ( $T_{\mathrm{g}}$ to $\left.T_{0}\right)$.

If the $R_{\mathrm{c}}-\Delta T_{\mathrm{x}}$ diagram is studied carefully, it becomes apparent that there is a problem because the $\Delta T_{\mathrm{x}}$ cannot be calculated with equilibrium thermodynamic functions. The problem arises from the $\Delta T_{\mathrm{x}}$ being defined by $T_{\mathrm{x}}$ and $T_{\mathrm{g}}$; since they are both kinetic transformation temperatures. Consequently, Beukel and Sietsma ${ }^{18)}$ analyzed the glass transition phenomenon on the basis of the change in free volume. In this study, an equilibrium free volume is defined by $B$ and $T_{0}$ in the VFT equation for viscosity, and then the change in free volume from a non-equilibrium to an equilibrium state is numerically analyzed on the basis of a non-linear differential equation. As a result of this analysis, the glass transition of metallic glasses is described quantitatively under the condi- 
tions where the experimental thermal analyses are made at a constant heating rate. ${ }^{18)}$

In accordance with the above-described model, we can calculate the $\Delta T_{\mathrm{x}}$ by solving the differential equation using the VFT parameters for viscosity. Furthermore, we can analyze theoretically all the GFA factors and their relationship by combining them with the previous result ${ }^{17)}$ of $R_{\mathrm{c}}-T_{\mathrm{g}} / T_{\mathrm{m}}$ which was calculated with the same VFT parameters. However, analyzing the differential equation frequently causes the following problems. For instance, it is difficult to obtain general solutions from the non-linear differential equation. Furthermore, the calculation process must suppress overshooting by using appropriate time intervals. Therefore, more efficient approaches for calculating the $\Delta T_{\mathrm{x}}$ are needed in order to avoid these problems, e.g., by a method of obtaining the approximate solution from the differential equation.

This paper has the following four purposes: (1) to calculate the $\Delta T_{\mathrm{x}}$ by solving the differential equation in accordance with the method developed by Beukel and Sietsma, (2) to establish the $R_{\mathrm{c}}-\Delta T_{\mathrm{x}}$ diagram for typical metallic glasses found to date, (3) to derive an approximate solution from the differential equation, and (4) to clarify the relationship between the VFT parameters and the set of factors $\left(R_{\mathrm{c}}, T_{\mathrm{g}} / T_{\mathrm{m}}\right.$ and $\Delta T_{\mathrm{x}}$ ) which are used for estimating the GFA of metallic glasses.

\section{Calculation Method}

The calculation method of $\Delta T_{\mathrm{x}}$ for metallic glasses followed the method previously devised by Beukel and Sietsma. ${ }^{18)}$

First, the equilibrium free volume $\left(\mathrm{x}_{\mathrm{eq}}\right)$ is defined by eq. (1) with $B$ and $T_{0}$ of the VFT parameters:

$$
\mathrm{x}_{\mathrm{eq}}=\frac{T-T_{0}}{B} \text {. }
$$

Equation (1) is related to equilibrium viscosity $\left(\eta_{\mathrm{eq}}\right)$,

$$
\eta_{\mathrm{eq}}=\eta_{0} \exp \left(\frac{B}{T-T_{0}}\right)=\eta_{0} \exp \left(\mathrm{x}_{\mathrm{eq}}^{-1}\right),
$$

expressed by the VFT equation for viscosity. In the calculation, the free volume $(\mathrm{x})$ and $\mathrm{x}_{\mathrm{eq}}$ are essentially converted to flow defect concentration $\left(\mathrm{C}_{\mathrm{f}}\right)$ and equilibrium concentration $\left(\mathrm{C}_{\mathrm{fe}}\right)$, respectively, with the following definitions, ${ }^{18)}$

$$
\begin{aligned}
\mathrm{C}_{\mathrm{f}} & =\exp \left(-\frac{1}{\mathrm{x}}\right), \\
\mathrm{C}_{\mathrm{fe}} & =\exp \left(-\frac{1}{\mathrm{x}_{\mathrm{eq}}}\right) .
\end{aligned}
$$

Then, the $\mathrm{dx} / \mathrm{d} T$ is assumed ${ }^{18)}$ to be proportional to the specific heat $\left(\left(\Delta \mathrm{C}_{\mathrm{p}}\right)_{\mathrm{fv}}\right):\left(\left(\Delta \mathrm{C}_{\mathrm{p}}\right)_{\mathrm{fv}}\right) \propto \mathrm{dx} / \mathrm{d} T$.

Equation (4) shows the differential equation which describes the kinetic behavior of the free volume from a nonequilibrium to an equilibrium state:

$$
\frac{\mathrm{dC}_{\mathrm{f}}}{\mathrm{d} t}=-k \mathrm{C}_{\mathrm{f}}\left(\mathrm{C}_{\mathrm{f}}-\mathrm{C}_{\mathrm{fe}}\right),
$$

where $k$ is the rate constant, which is expressed by Arrhenius formula shown in eq. (5),

$$
k=C_{0} \exp \left(-E_{\mathrm{f}} / R T\right),
$$

with the activation energy $\left(E_{\mathrm{f}}\right)$ and pre-exponential constant $\left(C_{0}\right)$. The $E_{\mathrm{f}}$ and $C_{0}$ used in the present calculation were $160 \mathrm{~kJ} / \mathrm{mol}$ and $2.1 \times 10^{23} \mathrm{~s}^{-1}$, respectively, which are the same as those used in a previous study. ${ }^{18)}$

By solving eq. (4) under a constant heating rate, we can obtain the temperature dependence of $\mathrm{x}$ as illustrated in Fig. 1(a). ${ }^{18)}$ The $\mathrm{dx} / \mathrm{d} T$ profile shown in Fig. 1(b) is assumed to hold the relation $\left(\Delta \mathrm{C}_{\mathrm{p}}\right)_{\mathrm{fv}} \propto \mathrm{dx} / \mathrm{d} T$ in the temperature range from $\mathrm{C}$ to $\mathrm{F}$ denoted in Fig. 1(a). On the basis of Figs. 1(a) and (b), Beukel and Sietsma defined the $T_{\mathrm{x}}$ and $T_{\mathrm{g}}$ as follows: the metallic glass crystallizes at $\mathrm{F}$, and the glass transition occurs in the curve DEF where the $\mathrm{dx} / \mathrm{d} T$ exhibits a sharp rise, e.g. at $E$.

Equation (4) indicates that the kinetic process of $\mathrm{C}_{\mathrm{f}}$ can be divided into three stages. The first stage is the region where $\mathrm{C}_{\mathrm{fe}} \ll \mathrm{C}_{\mathrm{f}}$; the $\mathrm{C}_{\mathrm{f}}$ decreases with the reaction of the second order. The second stage coincides with the point $\mathrm{D}$ in Fig. 1(a), where the rate of the change in $\mathrm{C}_{\mathrm{f}}$ is apparently zero because of $\mathrm{C}_{\mathrm{fe}}=\mathrm{C}_{\mathrm{f}}$. The final stage is a high temperature range corresponding to the curve DEF where $\mathrm{C}_{\mathrm{f}}<\mathrm{C}_{\mathrm{fe}}$. At the final stage, the $\left(\mathrm{C}_{\mathrm{f}}-\mathrm{C}_{\mathrm{fe}}\right)$ term of eq. (4) becomes negative, giving an increase in $\mathrm{C}_{\mathrm{f}}$. One can calculate the time evolution of $\mathrm{C}_{\mathrm{f}}$ by eq. (4) with the constants $E_{\mathrm{f}}, C_{0}, x_{0}, B$ and $T_{0}$. In the present study, heating rate is fixed at $0.67 \mathrm{~K} / \mathrm{s}$.

The critical cooling rate for formation of a glassy phase $\left(R_{\mathrm{c}}\right)$ was taken from our previous results ${ }^{17)}$ calculated from an isothermal transformation diagram which expresses the crystallization of metallic glasses. In this study, the following equation is proposed from Davies's equation ${ }^{4)}$ to describe the

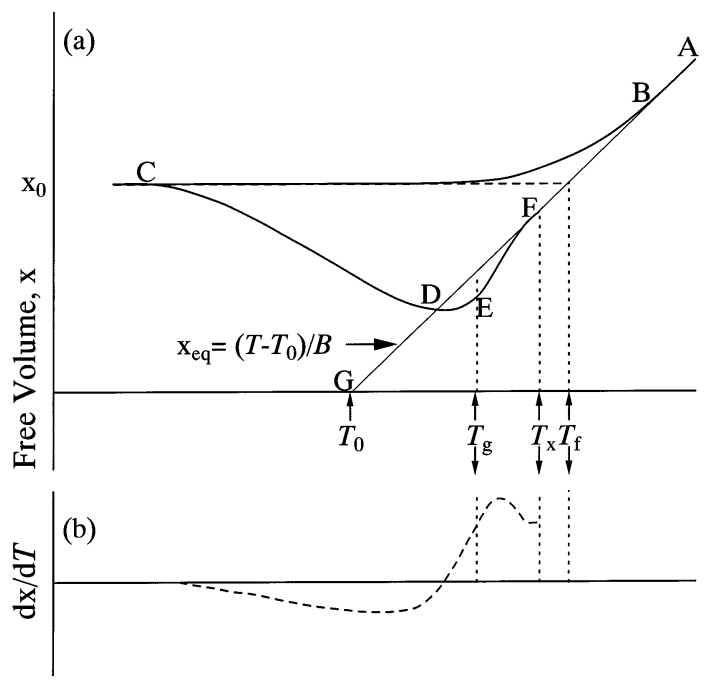

Temperature, $T$

Fig. 1 Schematic diagrams showing the changes in (a) free volume (x) and (b) $\mathrm{dx} / \mathrm{d} T$ with temperature of a metallic glass during rapid quenching (A to $\mathrm{C}$ ) and subsequent continuous heating (C to F). ${ }^{18)} B$ : VFT parameter, $T_{0}$ : ideal glass transition temperature, $T_{\mathrm{g}}$ : glass transition temperature, $T_{\mathrm{x}}$ : onset temperature of crystallization, $T_{\mathrm{f}}$ : fictive temperature, $x_{0}$ : initial free volume, $\mathrm{x}_{\mathrm{eq}}$ : equilibrium free volume. 
transformation curve (C-curve):

$$
\begin{aligned}
t= & {\left[\frac{31}{k_{\mathrm{B}}}\left(\frac{\mathrm{X} a_{0}^{9}}{N_{\mathrm{v}}}\right)^{1 / 4}\right] } \\
& \times\left[\frac{1}{\mathrm{~T}_{\mathrm{r}} \Delta \mathrm{T}_{\mathrm{r}}^{3 / 4}} \exp \left(\frac{0.268}{\mathrm{~T}_{\mathrm{r}}^{3} \Delta \mathrm{T}_{\mathrm{r}}^{2}}\right) \exp \left\{\frac{2}{5}\left(\frac{\mathrm{T}_{\mathrm{r}}}{\Delta \mathrm{T}_{\mathrm{r}}}\right)^{3 / 4}\right\}\right] \\
& \times\left[\eta_{0 \mathrm{r}} \exp \left(\frac{B_{\mathrm{r}}}{\mathrm{T}_{\mathrm{r}}-\mathrm{T}_{0 \mathrm{r}}}\right)\right] .
\end{aligned}
$$

Here, $k_{\mathrm{B}}$ is the Boltsmann constant, $T$ is the absolute temperature, $\mathrm{X}$ is the fraction of crystal formed in time $t, a_{0}$ is the mean atomic diameter, and $N_{\mathrm{v}}$ is the volume concentration of atoms. The $\mathrm{T}_{\mathrm{r}}\left(=T / T_{\mathrm{m}}\right)$ is the reduced temperature defined by $T$ normalized by melting temperature $T_{\mathrm{m}}$, and $\Delta \mathrm{T}_{\mathrm{r}}\left(=1-\mathrm{T}_{\mathrm{r}}\right)$ is the reduced undercooling of the melt. The C-curve is then calculated in the $\mathrm{T}-\mathrm{T}_{\mathrm{r}}-\mathrm{T}$ diagram for metallic glasses where $\mathrm{X}=10^{-6}, a_{0}=0.226 \mathrm{~nm}$, and $N_{\mathrm{v}}=6.2 \times 10^{28}$ molecules $/ \mathrm{m}^{3}$. In the calculation, the necessary parameters are as follows: reduced VFT parameters $\left(\eta_{0 \mathrm{r}}, \mathrm{B}_{\mathrm{r}}, \mathrm{T}_{0 \mathrm{r}}\right)$ which are the VFT parameters normalized by $T_{\mathrm{m}}$. Then, the $R_{\mathrm{c}}$ is calculated by $R_{\mathrm{c}}=R_{\mathrm{cr}} \times T_{\mathrm{m}}$ where $R_{\mathrm{cr}}$ (reduced critical cooling rate) is defined by the point of contact between the tangent of the C-curve and $R_{\mathrm{r}}$ in the $\mathrm{T}-\mathrm{T}_{\mathrm{r}}-\mathrm{T}$ diagram. The systems, and parameters used for the calculation $^{2,4,12,13,19-21)}$ and the calculated $R_{\mathrm{c}}{ }^{17)}$ are summarized in Table 1.

\section{Results}

Figures 2(a) and (b) show the plots of $\mathrm{x}$ and $\mathrm{dx} / \mathrm{d} T$ for a $\mathrm{Zr}_{41.2} \mathrm{Ti}_{13.8} \mathrm{Cu}_{12.5} \mathrm{Ni}_{10} \mathrm{Be}_{22.5}$ system. The $\mathrm{dx} / \mathrm{d} T$ exhibits tem-

Table 1 Representative metallic glasses found to date, Vogel-FulcherTammann (VFT) parameters ( $B$ and $T_{0}$ ), and calculated $R_{\mathrm{c}}$. The $R_{\mathrm{c}}$ was calculated from the time-transformation diagram which was obtained us-

\begin{tabular}{|c|c|c|c|c|}
\hline Alloy & $B / \mathrm{K}$ & $T_{0} / \mathrm{K}$ & Ref. & $R_{\mathrm{c}}$ \\
\hline $\mathrm{Ni}$ & 4700 & 295 & \multirow{11}{*}{ 4) } & $9.0 \times 10^{8}$ \\
\hline $\mathrm{Fe}_{83} \mathrm{~B}_{17}$ & 4630 & 638 & & $2.3 \times 10^{6}$ \\
\hline $\mathrm{Co}_{75} \mathrm{Si}_{15} \mathrm{~B}_{10}$ & 4190 & 675 & & $7.5 \times 10^{5}$ \\
\hline $\mathrm{Fe}_{79} \mathrm{Si}_{10} \mathrm{~B}_{11}$ & 4505 & 701 & & $5.0 \times 10^{5}$ \\
\hline $\mathrm{Fe}_{80} \mathrm{P}_{13} \mathrm{C}_{7}$ & 4600 & 616 & & $5.5 \times 10^{4}$ \\
\hline $\mathrm{Ni}_{75} \mathrm{Si}_{8} \mathrm{~B}_{17}$ & 4280 & 670 & & $1.8 \times 10^{5}$ \\
\hline $\mathrm{Pt}_{60} \mathrm{Ni}_{15} \mathrm{P}_{25}$ & 3560 & 405 & & $9.6 \times 10^{3}$ \\
\hline $\mathrm{Pd}_{82} \mathrm{Si}_{18}$ & 3730 & 557 & & $5.1 \times 10^{3}$ \\
\hline $\mathrm{Ni}_{62.4} \mathrm{Nb}_{37.6}$ & 5380 & 810 & & $2.9 \times 10^{3}$ \\
\hline $\mathrm{Pd}_{77.5} \mathrm{Cu}_{6} \mathrm{Si}_{16.5}$ & 3820 & 553 & & $1.0 \times 10^{3}$ \\
\hline $\mathrm{Pd}_{40} \mathrm{Ni}_{40} \mathrm{P}_{20}$ & 3600 & 509 & & $1.6 \times 10^{2}$ \\
\hline $\mathrm{Pd}_{40} \mathrm{Cu}_{30} \mathrm{Ni}_{10} \mathrm{P}_{20}$ & 4135 & 447 & 2) & $1.4 \times 10^{-3}$ \\
\hline $\mathrm{Zr}_{46.75} \mathrm{Ti}_{8.25} \mathrm{Cu}_{7.5} \mathrm{Ni}_{10} \mathrm{Be}_{27.5}$ & 7431 & 413 & \multirow{2}{*}{ 13) } & $8.7 \times 10^{0}$ \\
\hline $\mathrm{Zr}_{41.2} \mathrm{Ti}_{13.8} \mathrm{Cu}_{12.5} \mathrm{Ni}_{10} \mathrm{Be}_{22.5}$ & 8444 & 372 & & $1.3 \times 10^{1}$ \\
\hline $\mathrm{Nd}_{13} \mathrm{Fe}_{79} \mathrm{~B}_{8}$ & 6587 & 500 & \multirow{2}{*}{ 12) } & $6.4 \times 10^{2}$ \\
\hline $\mathrm{Nd}_{16} \mathrm{Fe}_{76} \mathrm{~B}_{8}$ & 12700 & 340 & & $4.8 \times 10^{1}$ \\
\hline $\mathrm{Mg}_{65} \mathrm{Cu}_{25} \mathrm{Y}_{10}$ & 5746 & 260 & 19) & $3.4 \times 10^{1}$ \\
\hline $\mathrm{Mg}_{65} \mathrm{Ni}_{20} \mathrm{Nd}_{15}$ & 1362.5 & 366.6 & \multirow{2}{*}{ 20) } & $1.8 \times 10^{-3}$ \\
\hline $\mathrm{Mg}_{65} \mathrm{Ni}_{20} \mathrm{Nd}_{15}$ & 24433 & 70 & & $1.7 \times 10^{-1}$ \\
\hline $\mathrm{SiO}_{2}$ & 34548 & 526 & 21) & $5.4 \times 10^{-7}$ \\
\hline
\end{tabular}
ing the VFT parameters. The data for $\mathrm{Ni}$ and $\mathrm{SiO}_{2}$ are shown for comparison. perature dependence similar to that of the specific heat profile of the metallic glasses as illustrated in Fig. 1(b). On the basis of the definitions described in section 2 , the $T_{\mathrm{x}}$ and $T_{\mathrm{g}}$ are determined as 638 and $660 \mathrm{~K}$, respectively, and the resulting $\Delta T_{\mathrm{x}}$ is calculated as $22 \mathrm{~K}$. The $T_{\mathrm{x}}$ and $T_{\mathrm{g}}$ determined for this alloy are also shown in Fig. 2(b). From this figure, the $d x / d T$ at $T_{\mathrm{x}}$ and $T_{\mathrm{g}}$ exactly corresponds to the value of $1.18 \times 10^{-4}$ which is equal to $1 / B$ in accordance with the definition in eq. (1). The details of the $T_{\mathrm{g}}$ and $T_{\mathrm{x}}$ are also shown in Fig. 2(c).

Figure 3 shows the plots of $\mathrm{dx} / \mathrm{d} T$ for $\mathrm{Ni}$, metallic glasses $\left(\mathrm{Fe}_{83} \mathrm{~B}_{17}, \quad \mathrm{Pd}_{40} \mathrm{Cu}_{30} \mathrm{Ni}_{10} \mathrm{P}_{20}, \quad \mathrm{Mg}_{65} \mathrm{Ni}_{20} \mathrm{Nd}_{15}\right.$, $\mathrm{Zr}_{46.75} \mathrm{Ti}_{8.25} \mathrm{Cu}_{7.5} \mathrm{Ni}_{10} \mathrm{Be}_{27.5}$ ) and $\mathrm{SiO}_{2}$ systems. The upward and downward pointing arrows show the $T_{\mathrm{g}}$ and $T_{\mathrm{x}}$, respectively, and the resulting $\Delta T_{\mathrm{x}}$ is $20 \mathrm{~K}$ for $\mathrm{Ni}, 7 \mathrm{~K}$ for $\mathrm{Fe}_{83} \mathrm{~B}_{17}$, $11 \mathrm{~K}$ for $\mathrm{Pd}_{40} \mathrm{Cu}_{30} \mathrm{Ni}_{10} \mathrm{P}_{20}, 50 \mathrm{~K}$ for $\mathrm{Mg}_{65} \mathrm{Ni}_{20} \mathrm{Nd}_{15}, 20 \mathrm{~K}$ for $\mathrm{Zr}_{46.75} \mathrm{Ti}_{8.25} \mathrm{Cu}_{7.5} \mathrm{Ni}_{10} \mathrm{Be}_{27.5}$, and $56 \mathrm{~K}$ for the $\mathrm{SiO}_{2}$ system. From this figure, it is apparent that the $\Delta T_{\mathrm{x}}$ is independent of $T_{\mathrm{g}}$, but depends on $1 / B$ as well as the maximum value of

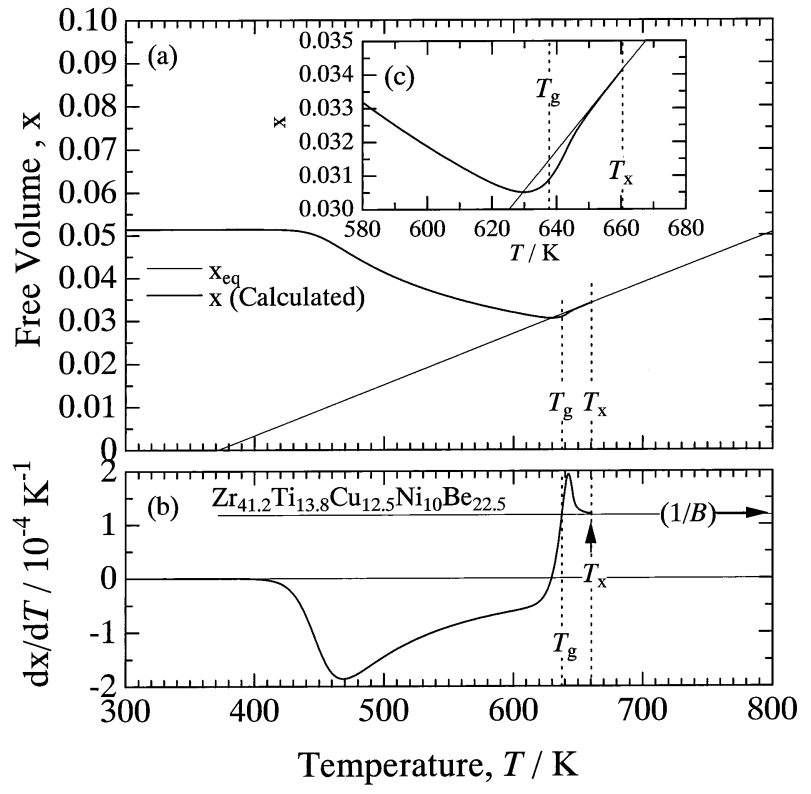

Fig. 2 Changes in (a), (c) free volume (x), and (b) $\mathrm{dx} / \mathrm{d} T$ for $\mathrm{Zr}_{41.2} \mathrm{Ti}_{13.8} \mathrm{Cu}_{12.5} \mathrm{Ni}_{10} \mathrm{Be}_{22.5}$ system.

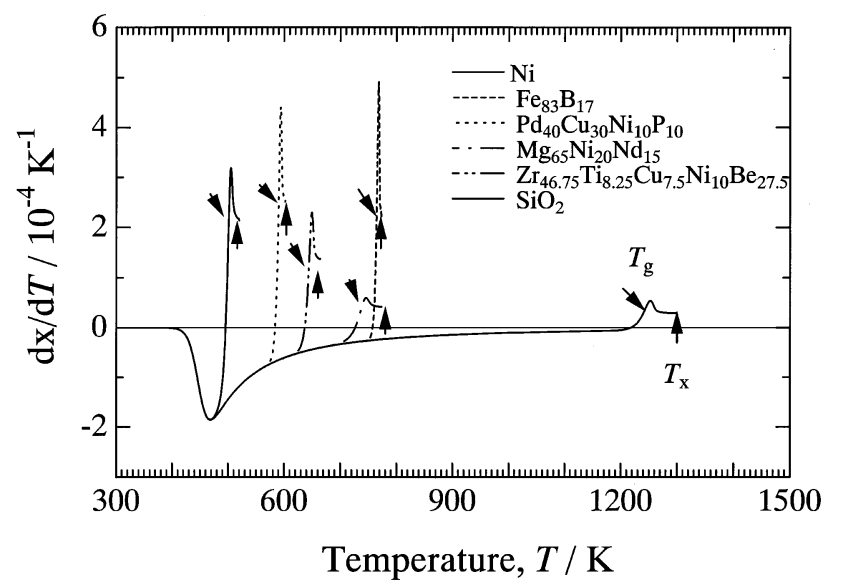

Fig. 3 Plots of $\mathrm{dx} / \mathrm{d} T$ for $\mathrm{Ni}$, metallic glasses $\left(\mathrm{Fe}_{83} \mathrm{~B}_{17}, \mathrm{Pd}_{40} \mathrm{Cu}_{30} \mathrm{Ni}_{10} \mathrm{P}_{20}\right.$, $\left.\mathrm{Mg}_{65} \mathrm{Ni}_{20} \mathrm{Nd}_{15}, \mathrm{Zr}_{46.75} \mathrm{Ti}_{8.25} \mathrm{Cu}_{7.5} \mathrm{Ni}_{10} \mathrm{Be}_{27.5}\right)$ and $\mathrm{SiO}_{2}$ systems. 

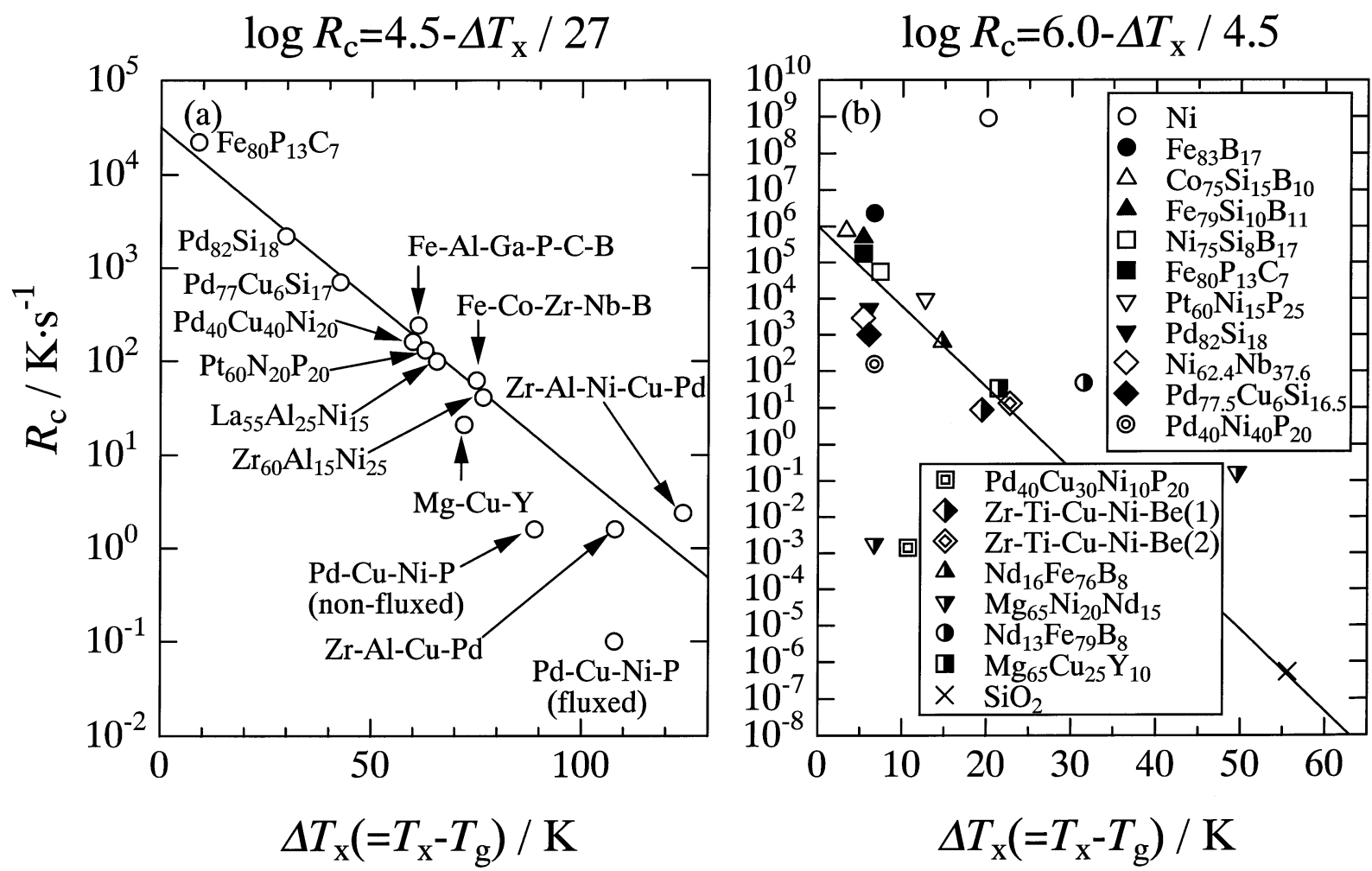

Fig. 4 (a) Experimental data on the $R_{\mathrm{c}}-\Delta T_{\mathrm{x}}$ diagram for metallic glasses, ${ }^{2)}$ and (b) calculated data for $\mathrm{Ni}$, metallic glasses and $\mathrm{SiO} 2$ systems.

the $\mathrm{dx} / \mathrm{d} T$. This tendency implies that the $\Delta T_{\mathrm{x}}$ is in proportion to $B$.

Figure 4(a) shows the $R_{\mathrm{c}}-\Delta T_{\mathrm{x}}$ diagram experimentally determined for several metallic glasses, ${ }^{2)}$ and Fig. 4(b) is the calculated results for $\mathrm{Ni}$, the metallic glasses and $\mathrm{SiO}_{2}$ systems. In Fig. 4(a), there is a linear relationship between $\log R_{\mathrm{c}}$ and $\Delta T_{\mathrm{x}}$ which can be expressed as $\left(\log R_{\mathrm{c}}=4.5-\Delta T_{\mathrm{x}} / 27\right)$ by the least-squares method. One can also see a similar relationship in Fig. 4(b), though some plots deviate from the line ( $\left.\log R_{\mathrm{c}}=6.0-\Delta T_{\mathrm{x}} / 4.5\right)$ obtained by the same method.

Another feature of the calculated $R_{\mathrm{c}}-\Delta T_{\mathrm{x}}$ diagram in Fig. 4(b) is that the calculated $\Delta T_{\mathrm{x}}$ is smaller than the experimental result. For instance, $\Delta T_{\mathrm{x}}$ of the $\mathrm{Pd}_{40} \mathrm{Cu}_{30} \mathrm{Ni}_{10} \mathrm{P}_{20}$ alloy is calculated to be nearly ten times smaller than that in the experimental results, though the calculated $R_{\mathrm{c}}$ approximately agrees with the experimental result. On average, the values of $\Delta T_{\mathrm{x}}$ in Fig. 4(b) are approximately six times smaller than that in the experimental results in Fig. 4(a).

\section{Discussion}

In this section, we will focus on the following points: (1) analysis of an approximate solution for the differential equation, (2) the reason for the discrepancy between the calculated and experimental $\Delta T_{\mathrm{x}}$, and (3) analysis of the relationship between the VFT parameters and the set of factors $\left(R_{\mathrm{c}}, T_{\mathrm{g}} / T_{\mathrm{m}}\right.$ and $\left.\Delta T_{\mathrm{x}}\right)$ which are used for the estimation of GFA.

\subsection{Analysis of an approximate solution for the differen- tial equation}

As shown in the previous section, the differential equation was analyzed numerically in order to obtain the temperature dependence of $\mathrm{x}$, and the resulting $\Delta T_{\mathrm{x}}$. In solving the differential equation, however, we often encounter some difficulties. For instance, appropriate time intervals must be selected during the calculation in order to prevent the calculation from overshooting, which leads to a prolonged calculation time. Furthermore, one must analyze the equations one by one for each metallic glass, indicating the difficulty of obtaining general solutions. In order to overcome these difficulties, we obtain the approximate solution of eq. (4).

Although eq. (4) is a form of the Bernoulli equation of which the solution is mathematically obtainable, one cannot obtain the solution of eq. (4) by the analysis method for the following three reasons. The first arises from the nonlinearity of the differential equation, and the second results from the temperature dependence of $k$ in eq. (5). The third reason originates from the coexistence of different types of temperature dependence of the terms: Arrhenius type for $k$, and the VFT type for $\mathrm{C}_{\mathrm{fe}}$. Accordingly, an approximate solution is obtained by assuming that the solution consists of two linear terms corresponding to the first and the third regions described in Section 2. These linear terms are separately analyzed as follows.

Equation (7) shows eq. (4) again with the expanded terms on the right-hand side:

$$
\frac{\mathrm{dC}_{\mathrm{f}}}{\mathrm{d} t}=-k \mathrm{C}_{\mathrm{f}}^{2}+k \mathrm{C}_{\mathrm{fe}} \mathrm{C}_{\mathrm{f}}
$$

First, we focus on the first term on the right-hand side in order to obtain the approximate solution corresponding to the first 
region. Ignoring the second term, we can write eq. (7) as,

$$
\frac{1}{\mathrm{C}_{\mathrm{f}}^{2}} \mathrm{dC}_{\mathrm{f}}=-k \mathrm{~d} t
$$

Equation (8) expresses a decrease in $\mathrm{C}_{\mathrm{f}}$ as well as $x$ with time because of the relaxation of metallic glasses on heating. It is to be noted that eq. (8) is a linear differential equation which can generally be solved by the analysis method. The variation $t$ is then converted to $T^{*}(=1 / T)$ through $T$ in order to integrate both sides of eq. (8). This is due to the previous results ${ }^{22,23)}$ that eq. (5) can be expressed as $\left(\mathrm{dC}_{\mathrm{f}} / \mathrm{d} t\right)=\left(\mathrm{dC}_{\mathrm{f}}\right) /(\mathrm{d} T) \alpha$. By designating $\alpha$ as a heating rate, we obtain the following equation from eq. (8):

$$
\int \frac{1}{\mathrm{C}_{\mathrm{f}}^{2}} \mathrm{dC}_{\mathrm{f}}=C_{0} \int \frac{\exp \left(-\frac{E_{\mathrm{f}}}{R} T^{*}\right)}{T^{* 2}} \mathrm{~d} T^{*} .
$$

The $T^{* 2}$ term in the right-hand side of eq. (9) appears from the integrating factor when the variable $T$ is converted to $T^{*}$,

$$
\mathrm{d} T=-\frac{1}{T^{* 2}} \mathrm{~d} T^{*}
$$

By integrating the right-hand side in eq. (9) with respect to $T^{*}$, we can obtain the time evolution of $\mathrm{C}_{\mathrm{f}}$ as an infinite multinomial series. ${ }^{24)}$ However, the approximate solution as an infinite formula is not useful in the analysis of $\mathrm{x}$. Therefore, we apply the following approximation to eq. (9),

$$
C_{0}^{\prime}=C_{0} T^{* 2}
$$

in order to obtain the solution of eq. (9) as a single term integrand of the elementary functions. Here, $C_{0}^{\prime}$ depends on $C_{0}$ as well as $E_{\mathrm{f}}$ of eq. (5). For the present calculation constants $\left(E_{\mathrm{f}}=160 \mathrm{~kJ} / \mathrm{mol}^{-1}\right.$ and $\left.C_{0}=2.1 \times 10^{23} \mathrm{~s}^{-1}\right)$, the value of $C_{0}^{\prime}$ was obtained by the least-squares method as $C_{0}^{\prime}=2.1 \times 10^{31} \mathrm{~s}^{-1}$ which was approximated to fit $k$ in eq. (5) at temperatures ranging from 0 to $2000 \mathrm{~K}$. The validity for this approximation will be discussed later. Now, eq. (9) can be written as,

$$
\int \frac{1}{\mathrm{C}_{\mathrm{f}}^{2}} \mathrm{dC}_{\mathrm{f}}=C_{0}^{\prime} \int \exp \left(-\frac{E_{\mathrm{f}}}{R} T^{*}\right) \mathrm{d} T^{*},
$$

which yields a linear solution of eq. (9):

$$
\mathrm{C}_{\mathrm{f}}=\frac{\mathrm{C}_{\mathrm{f} 0}}{\left\{1+\frac{C_{0}^{\prime} R}{E_{\mathrm{f}} \alpha} \mathrm{C}_{\mathrm{f} 0} \exp \left(-\frac{E_{\mathrm{f}}}{R T}\right)\right\}} .
$$

Here, $\mathrm{C}_{\mathrm{f} 0}$ is the initial value of $\mathrm{C}_{\mathrm{f}}\left(3.55 \times 10^{-9}\right)$ calculated by eq. (3) with $\mathrm{x}_{0}=0.0514$.

Second, the approximate solution corresponding to the third region is analyzed. This solution is another linear solution of eq. (7) in the higher temperature range. The solution is in the following form,

$$
\mathrm{C}_{\mathrm{f}}=\exp \left(-\frac{B}{T-T_{0}}\right),
$$

which is the concentration expression of $\mathrm{x}_{\mathrm{eq}}$. This is because the solution at $T \gg T_{\mathrm{x}}$ follows $\mathrm{C}_{\mathrm{eq}}\left(\mathrm{x}_{\mathrm{eq}}\right)$ as illustrated by the line AG in Fig. 1,

Having obtained the linear solutions of eq. (7) correspond- ing to the first and the third region, we apply the final assumption that the approximate solution of eq. (7) is the sum of eqs. (13) and (14).

$$
\mathrm{C}_{\mathrm{f}}=\frac{\mathrm{C}_{\mathrm{f} 0}}{\left\{1+\frac{C_{0}^{\prime} R}{E_{\mathrm{f}} \alpha} \mathrm{C}_{\mathrm{f} 0} \exp \left(-\frac{E_{\mathrm{f}}}{R T}\right)\right\}}+\exp \left(-\frac{B}{T-T_{0}}\right) .
$$

Figure 5 shows, as before in Fig. 2, the plots of $\mathrm{x}$ and $\mathrm{dx} / \mathrm{d} T$ for $\mathrm{Zr}_{41.2} \mathrm{Ti}_{13.8} \mathrm{Cu}_{12.5} \mathrm{Ni}_{10} \mathrm{Be}_{22.5}$, respectively, with the approximate solution $\left(\mathrm{x}_{\mathrm{ap}}\right)$ calculated by eq. (15). From these figures, $x_{\text {ap }}$ fits the solution numerically analyzed $\left(x_{n u}\right)$ by eq. (4) in the temperature range of 300 to $800 \mathrm{~K}$. This indicates that the value of $C_{0}^{\prime}$ introduced thus is appropriately fitted for $C_{0}$ and $E_{\mathrm{f}}$ in eq. (5).

Figure 5(c) shows the temperature dependence of $x_{\text {ap }}$ near $T_{\mathrm{g}}$ in more detail. From Fig. 5(c), $T_{\mathrm{g}}$ and $\Delta T_{\mathrm{x}}$ can be obtained substitutionally from the following specific temperatures: $T_{\text {trans.s }}$ and $T_{\text {trans.f. }}$ These temperatures are defined by the temperature where $\mathrm{x}_{\mathrm{ap}}$ separates from a linear solution $\left(\mathrm{x}_{\text {lin }}\right)$ calculated by eq. (13), and where $\mathrm{x}_{\text {ap }}$ coincides with $\mathrm{x}_{\mathrm{eq}}$ obtained by eq. (14), respectively. From the figure, $T_{\mathrm{x}}$ is obtained from $\mathrm{x}_{\text {ap }}$ because $T_{\text {trans.f }}$ exactly corresponds to $T_{\mathrm{x}}$. However, $T_{\mathrm{g}}$ cannot be determined in $\mathrm{x}_{\mathrm{ap}}$ for the following two reasons. First, $x_{\text {ap }}$ does not cross $x_{\text {eq }}$, in disagreement with the definition of $T_{\mathrm{g}}$ described in Section 2. Second, the $\mathrm{dx}_{\text {ap }} / \mathrm{d} T$ curve between $T_{\mathrm{g}}$ and $T_{\mathrm{x}}$ dose not have the projection part which is a characteristic of metallic glass in the specific heat curve. Although it is impossible to determine $T_{\mathrm{g}}$ in $\mathrm{x}_{\mathrm{ap}}$, the cross-point $\left(T_{\text {cross }}\right)$ between $\mathrm{x}_{\text {lin }}$ and $\mathrm{x}_{\mathrm{eq}}$ is plotted just near $T_{\mathrm{g}}$. By summarizing the above-described features of the specific temperatures, we can obtain the following estimations that $\Delta T_{\mathrm{x}}$ is in proportion to $\Delta T_{\text {trans }}\left(=T_{\text {trans.f }}-T_{\text {cross }}\right)$, and that $T_{\text {cross }}$ is substitutable for $T_{\mathrm{g}}$. These estimations are supported from $\Delta T_{\mathrm{x}}, \Delta T_{\text {cross }}$ and specific temperatures summa-

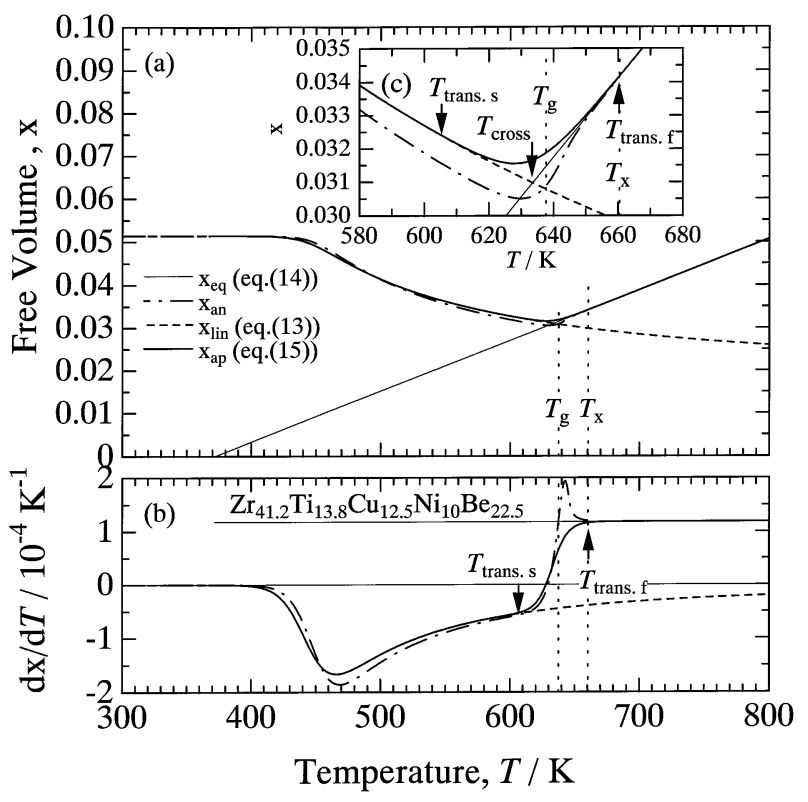

Fig. 5 Plots of (a) $\mathrm{x}$, (b) $\mathrm{dx} / \mathrm{d} T$ and the approximate solution $\left(\mathrm{x}_{\mathrm{ap}}\right)$ calculated by eq. (15) for $\mathrm{Zr}_{41.2} \mathrm{Ti}_{13.8} \mathrm{Cu}_{12.5} \mathrm{Ni}_{10} \mathrm{Be}_{22.5}$ metallic glass. (c) the details of the changes in the $\mathrm{x}$ and $\mathrm{x}_{\mathrm{ap}}$ near $T_{\mathrm{g}}$. 
Table 2 Calculated temperatures for $\mathrm{Ni}$, metallic glasses and $\mathrm{SiO}_{2}$ systems. The $T_{\mathrm{g}}^{\mathrm{Exp}}$ is the glass transition temperature experimentally determined, and refers to previous data. ${ }^{4)}$ The $\Delta T_{\text {cross }}$ is defined as $\Delta T_{\text {cross }}=T_{\mathrm{x}}-T_{\text {cross }}$ where $T_{\text {trans.f }}=T_{\mathrm{x}}$.

\begin{tabular}{cccccccc}
\hline Alloy & $T_{\text {trans.s }} / \mathrm{K}$ & $T_{\text {cross }} / \mathrm{K}$ & $T_{\mathrm{g}}^{\mathrm{Exp}} / \mathrm{K}$ & $T_{\mathrm{g}} / \mathrm{K}$ & $T_{\mathrm{x}} / \mathrm{K}$ & $\Delta T_{\mathrm{x}} / \mathrm{K}$ & $\Delta T_{\text {cross }}$ \\
\hline $\mathrm{Ni}$ & 458 & 480 & 425 & 500.3 & 520.4 & 20.1 & 40.4 \\
$\mathrm{Fe}_{83} \mathrm{~B}_{17}$ & 740 & 756 & 760 & 766.3 & 773.0 & 6.7 & 17.0 \\
$\mathrm{Co}_{75} \mathrm{Si}_{15} \mathrm{~B}_{10}$ & 765 & 775 & 785 & 789.1 & 792.5 & 3.4 & 17.5 \\
$\mathrm{Fe}_{79} \mathrm{Si}_{10} \mathrm{~B}_{11}$ & 797 & 810 & 818 & 820.6 & 826.0 & 5.4 & 16.0 \\
$\mathrm{Fe}_{80} \mathrm{P}_{13} \mathrm{C}_{7}$ & 718 & 733 & 736 & 745.6 & 752.9 & 7.3 & 19.9 \\
$\mathrm{Ni}_{75} \mathrm{Si}_{8} \mathrm{~B}_{17}$ & 762 & 775 & 782 & 786.4 & 791.8 & 5.4 & 16.8 \\
$\mathrm{Pt}_{60} \mathrm{Ni}_{15} \mathrm{P}_{25}$ & 512 & 528 & 500 & 543.2 & 555.9 & 12.7 & 27.9 \\
$\mathrm{Pd}_{82} \mathrm{Si}_{18}$ & 646 & 659 & 657 & 671.9 & 677.9 & 6.0 & 18.9 \\
$\mathrm{Ni}_{62.4} \mathrm{Nb}_{37.6}$ & 916 & 930 & 945 & 941.2 & 946.6 & 5.4 & 16.6 \\
$\mathrm{Pd}_{77.5} \mathrm{Cu}_{6} \mathrm{Si}_{16.5}$ & 645 & 659 & 653 & 671.2 & 677.2 & 6.0 & 18.2 \\
$\mathrm{Pd}_{40} \mathrm{Ni}_{40} \mathrm{P}_{20}$ & 601 & 615 & 602 & 627.6 & 634.3 & 6.7 & 19.3 \\
$\mathrm{Pd}_{40} \mathrm{Cu}_{30} \mathrm{Ni}_{10} \mathrm{P}_{20}$ & 560 & 578 & 581 & 591.5 & 602.2 & 10.7 & 24.2 \\
$\mathrm{Zr}_{46.75} \mathrm{Ti}_{8.25} \mathrm{Cu}_{7.5} \mathrm{Ni}_{10} \mathrm{Be}_{27.5}$ & 603 & 629 & 602 & 645.1 & 664.5 & 19.4 & 35.5 \\
$\mathrm{Zr}_{41.2} \mathrm{Ti}_{13.8} \mathrm{Cu}_{12.5} \mathrm{Ni}_{10} \mathrm{Be}_{22.5}$ & 592 & 620 & 595 & 637.7 & 660.5 & 22.8 & 40.5 \\
$\mathrm{Nd}_{13} \mathrm{Fe}_{79} \mathrm{~B}_{8}$ & 659 & 678 & - & 694.0 & 708.7 & 14.7 & 30.7 \\
$\mathrm{Nd}_{16} \mathrm{Fe}_{76} \mathrm{~B}_{8}$ & 652 & 683 & - & 703.3 & 734.8 & 31.5 & 51.8 \\
$\mathrm{Mg}_{65} \mathrm{Cu}_{25} \mathrm{Y}_{10}$ & 454 & 486 & 413 & 505.7 & 527.1 & 21.4 & 41.1 \\
$\mathrm{Mg}_{65} \mathrm{Ni}_{20} \mathrm{Nd}_{15}$ & 411 & 431 & 459.3 & 446.1 & 452.8 & 6.7 & 21.8 \\
$\mathrm{Mg}_{65} \mathrm{Ni}_{20} \mathrm{Nd}_{15}$ & 665 & 713 & 459.3 & 736.2 & 785.8 & 49.6 & 72.8 \\
$\mathrm{SiO}_{2}$ & 1175 & 1230 & 1495 & 1244.0 & 1299.6 & 55.6 & 69.6 \\
\hline
\end{tabular}

rized in Table 2. It is thus found that one can estimate $T_{\mathrm{g}}$ and $\Delta T_{\mathrm{x}}$ with the approximate solution of eq. (7) from the $\mathrm{x}-T$ diagram. This leads to an important result that one does not have to analyze the differential equation numerically in order to calculate the $\Delta T_{\mathrm{x}}$.

It is also to be noted in Fig. 5(c) that $\Delta T_{\text {trans }}$ has a relationship with the acute angle between $\mathrm{x}_{\mathrm{eq}}$ and $\mathrm{x}_{\text {lin }}$ at $T_{\text {cross }}$;

$$
\left.\Delta T_{\text {trans }} \propto \frac{\mathrm{d}\left(\mathrm{x}_{\mathrm{eq}}-\mathrm{x}_{\mathrm{lin}}\right)}{\mathrm{d} T}\right|_{T=T_{\text {trans }}} .
$$

Since $\mathrm{x}_{\text {lin }}$ is fixed in the present study, $\Delta T_{\text {trans }}$ depends on the value of $\mathrm{dx}_{\mathrm{eq}} / \mathrm{d} T(=1 / B)$. This is supported by the results in Fig. 3 that $\Delta T_{\mathrm{x}}$ is in proportion to $B$. Thus, the $\mathrm{x}-T$ diagram is useful for estimating $T_{\mathrm{g}}$ as well as $\Delta T_{\mathrm{x}}$.

Figure 6 shows the $\mathrm{x}-T$ diagram in which $\mathrm{x}_{\mathrm{ap}}$ and $\mathrm{x}_{\mathrm{eq}}$ for the systems listed in Table 1 are plotted. From this figure, one can estimate $T_{\mathrm{g}}$ for each system as the $T_{\text {cross }}$ between $\mathrm{x}_{\text {lin }}$ and $\mathrm{x}_{\mathrm{eq}}$ by the above-described method. Furthermore, $\Delta T_{\mathrm{x}}$ can be estimated by eq. (16). These results support the contention that the largest $\Delta T_{\mathrm{x}}$ can be calculated for the $\mathrm{SiO}_{2}$ system having low $T_{0}$ as well as the largest $B$.

\subsection{The reason for the discrepancy between the calcu- lated and experimental $\Delta T_{\mathrm{x}}$}

As shown in Fig. 4, the calculated values of $\Delta T_{\mathrm{x}}$ were approximately six times smaller than the experimental results. We will discuss the reason for this discrepancy on the basis of the definition of $T_{\mathrm{g}}$ and $T_{\mathrm{x}}$.

Figure 7 shows the plots of the calculated and experimental $T_{\mathrm{g}}$ for the systems listed in Table 1. The x- and y-axis show the experimentally obtained $\left(T_{\mathrm{g}}^{\mathrm{e}}\right)$ and the calculated $\left(T_{\mathrm{g}}^{\mathrm{c}}\right)$, respectively. From Fig. 7, the plots of the $T_{\mathrm{g}}$-values roughly lie along the broken line except for the $\mathrm{SiO}_{2}$ system, indicating the directly proportional relationship between the $T_{\mathrm{g}}$-values.

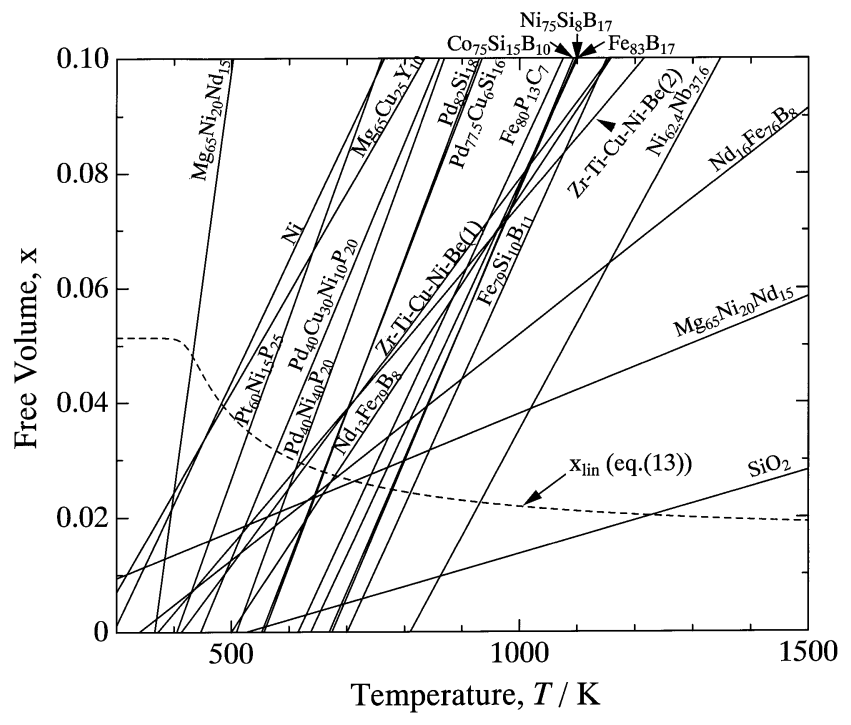

Fig. 6 Free volume-temperature $(\mathrm{x}-T)$ diagram in which the $\mathrm{x}_{\mathrm{ap}}$ and $\mathrm{x}_{\mathrm{eq}}$ for $\mathrm{Ni}$, metallic glasses and $\mathrm{SiO}_{2}$ systems are plotted.

This result implies that $T_{\mathrm{g}}$ is correctly calculated in the present model using the given $C_{0}$ and $E_{\mathrm{f}}$ values. It is thus suggested that the discrepancy in $\Delta T_{\mathrm{x}}$ results in the definition of $T_{\mathrm{x}}$.

As described in Section 2, $T_{\mathrm{x}}$ is defined as the temperature where $\mathrm{x}$ is exactly equal to $\mathrm{x}_{\mathrm{eq}}$. This definition of $T_{\mathrm{x}}$ is apparently a necessary condition; hence, other factors described below also affect $T_{\mathrm{x}}$.

The first factor is the relaxation due to the short-range order. As far as the relaxation is concerned, it has been pointed out $^{18)}$ that there are two types of relaxation: the topological short range order (TSRO) and the chemical short range order (CSRO). The former is due to the change in free volume: this is the form of relaxation which the present model deals 


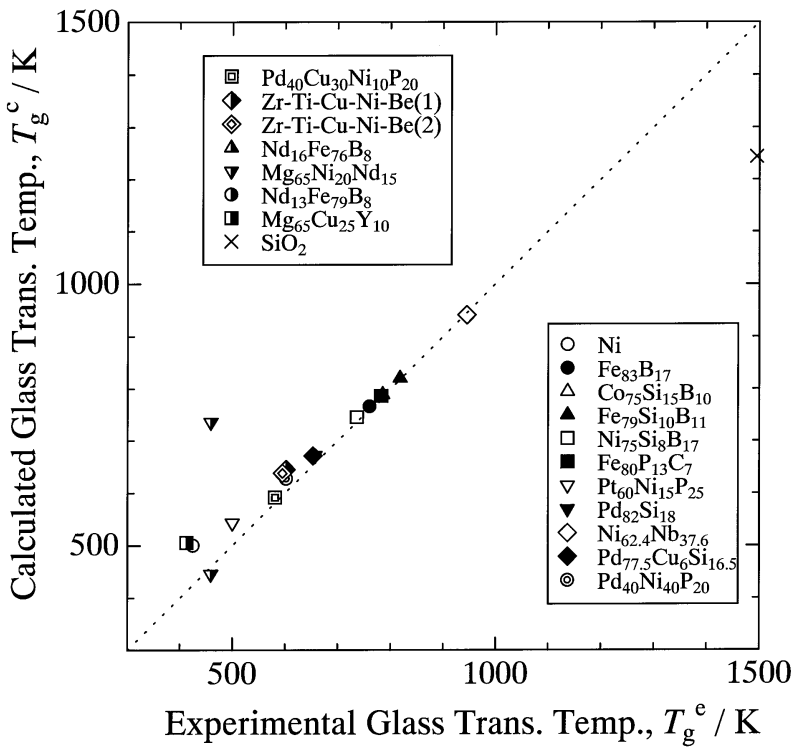

Fig. 7 Plots of the calculated and experimental $T_{\mathrm{g}}$ values for $\mathrm{Ni}$, metallic glasses and $\mathrm{SiO}_{2}$ systems.

with. By contrast, the CSRO cannot be taken into account for the present calculation model. Although the effect of CSRO on crystallization has not been clarified, the change in atomic configurations due to the CSRO causes an increase in $T_{\mathrm{x}}$.

The second factor is probably due to the difficulty of atomic rearrangements which stabilize the supercooled liquid and prevent crystallization. ${ }^{2)}$ For instance, it has been experimentally confirmed in thermal analysis that crystallization from the stabilized supercooled liquid occurs through simultaneous precipitation of more than two phases. ${ }^{2)}$ It has also been shown experimentally in a $\mathrm{Zr}-\mathrm{Al}-\mathrm{Cu}$ system that the appearance of the extremely large supercooled liquid range is attributable to retardation of growth of the $\mathrm{Zr}_{2}(\mathrm{Cu}, \mathrm{Al})$ phase. ${ }^{2)}$ This requires the long-range diffusion of $\mathrm{Al}$ to redistribute $\mathrm{Al}$ around $\mathrm{Zr}$ even in a highly dense random packed structure. Thus, the second factor is due to the difficulty in the precipitation of the crystalline phase from a stabilized supercooled liquid, a factor which cannot be taken into account in the present calculation model.

In addition to the above factors, $E_{\mathrm{f}}$ and $C_{0}$ can be factors affecting $\Delta T_{\mathrm{x}}$. First, we will discuss the validity of the calculation condition that $E_{\mathrm{f}}$ and $C_{0}$ are constants, which implies that they are independent in alloy systems. The values of $\left.\left(E_{\mathrm{f}}, C_{0}\right)=\left(160 \mathrm{~kJ} / \mathrm{mol}, 2.1 \times 10^{23} \mathrm{~s}^{-1}\right)^{18}\right)$ used in the present study were originally obtained for the Pdbased metallic glasses from the kinetics of free volume annihilation which were obtained from experiments on the isothermal changes in viscosity, resistivity, elastic constants etc. ${ }^{25-27)}$ The other sets of values used for the analysis of glass transition phenomena are exemplified as $\left(E_{\mathrm{f}}, C_{0}\right)=$ $\left(99 \mathrm{~kJ} / \mathrm{mol}^{-1}, 8.4 \times 10^{15} \mathrm{~s}^{-1}\right)$ for $\mathrm{Zr}_{65} \mathrm{Al}_{7.5} \mathrm{Ni}_{10} \mathrm{Cu}_{17.5}$ metallic glass, ${ }^{22)}$ and $\left(E_{\mathrm{f}}, C_{0}\right)=\left(250 \mathrm{~kJ} / \mathrm{mol}^{-1}, 1.63 \times 10^{25} \mathrm{~s}^{-1}\right)$ for $\mathrm{Fe}_{41.5} \mathrm{Ni}_{41.5} \mathrm{~B}_{17.5}$ metallic glass. ${ }^{28)}$ In order to estimate errors in $\Delta T_{\mathrm{x}}$ with the values of $E_{\mathrm{f}}$ and $C_{0}$, calculations were carried out for $\mathrm{Zr}_{65} \mathrm{Al}_{7.5} \mathrm{Ni}_{10} \mathrm{Cu}_{17.5}$ and $\mathrm{Fe}_{41.5} \mathrm{Ni}_{41.5} \mathrm{~B}_{17.5}$ metallic glasses as shown in Fig. 8. In the calculation, $B$ and $T_{0}$ of the $\mathrm{Fe}_{40} \mathrm{Ni}_{40} \mathrm{~B}_{20}{ }^{4)}$ were used instead of those of $\mathrm{Fe}_{41.5} \mathrm{Ni}_{41.5} \mathrm{~B}_{17.5}$ alloy because of the close similarity

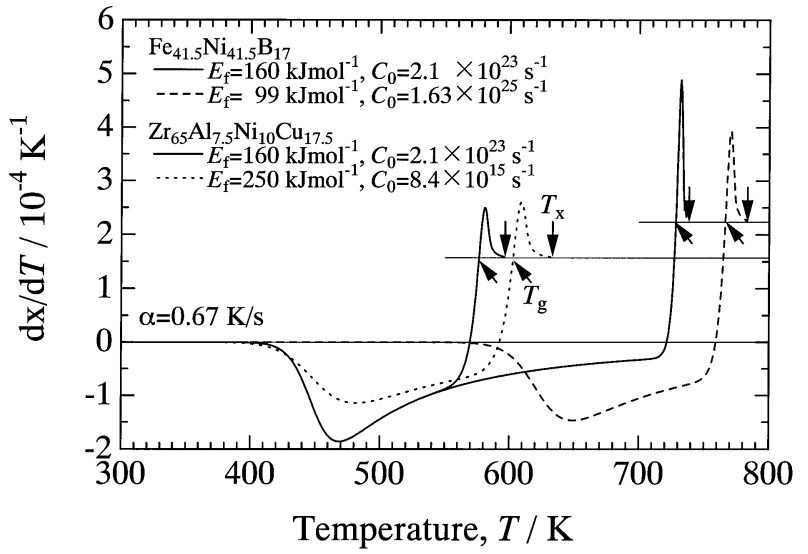

Fig. 8 The changes of $\mathrm{dx} / \mathrm{d} T$ profiles of $\mathrm{Fe}_{41.5} \mathrm{Ni}_{41.5} \mathrm{~B}_{17}$ and $\mathrm{Zr}_{65} \mathrm{Al}_{7.5}$ $\mathrm{Ni}_{10} \mathrm{Cu}_{17.5}$ calculated with $\left(E_{\mathrm{f}}, C_{0}\right)$ for both their intrinsic values and the present calculation conditions.

in the compositions. From the $\mathrm{dx} / \mathrm{d} T$ profiles in Fig. 8, the $\mathrm{Fe}_{41.5} \mathrm{Ni}_{41.5} \mathrm{~B}_{17.5}$ metallic glass shows $\Delta T_{\mathrm{x}}$ of $18 \mathrm{~K}$ for $\left(E_{\mathrm{f}}, C_{0}\right)=\left(99 \mathrm{~kJ} / \mathrm{mol}, 1.63 \times 10^{25} \mathrm{~s}^{-1}\right)$, and $10 \mathrm{~K}$ for $\left(E_{\mathrm{f}}, C_{0}\right)=\left(160 \mathrm{~kJ} / \mathrm{mol}, 2.1 \times 10^{23} \mathrm{~s}^{-1}\right)$. On the other hand, $\mathrm{Zr}_{65} \mathrm{Al}_{7.5} \mathrm{Ni}_{10} \mathrm{Cu}_{17.5}$ metallic glass shows $\Delta T_{\mathrm{x}}$ of $30 \mathrm{~K}$ for $\left(E_{\mathrm{f}}, C_{0}\right)=\left(250 \mathrm{~kJ} / \mathrm{mol}, 8.4 \times 10^{15} \mathrm{~s}^{-1}\right)$, and $20 \mathrm{~K}$ for $\left(E_{\mathrm{f}}, C_{0}\right)=\left(160 \mathrm{~kJ} / \mathrm{mol}, 2.1 \times 10^{23} \mathrm{~s}^{-1}\right)$. Thus, the difference in $\Delta T_{\mathrm{x}}$ is $8 \mathrm{~K}$ for $\mathrm{Fe}_{41.5} \mathrm{Ni}_{41.5} \mathrm{~B}_{17.5}$ and is $10 \mathrm{~K}$ for $\mathrm{Zr}_{65} \mathrm{Al}_{7.5} \mathrm{Ni}_{10} \mathrm{Cu}_{17.5}$ metallic glass. Accordingly the ratio between the $\Delta T_{\mathrm{x}}$ calculated with $\left(E_{\mathrm{f}}, C_{0}\right)=(160 \mathrm{~kJ} / \mathrm{mol}, 2.1 \times$ $\left.10^{23} \mathrm{~s}^{-1}\right)$ and with the intrinsic values are estimated as approximately $50 \%$. Thus, it is shown that no significant differences in $\Delta T_{\mathrm{x}}$ are seen in the calculation results although the calculations were carried out under the condition that $\left(E_{\mathrm{f}}, C_{0}\right)=\left(160 \mathrm{~kJ} / \mathrm{mol}, 2.1 \times 10^{23} \mathrm{~s}^{-1}\right)$ instead of the intrinsic values of $E_{\mathrm{f}}$ and $C_{0}$. This result enabled us to use $\left(E_{\mathrm{f}}, C_{0}\right)=\left(160 \mathrm{~kJ} / \mathrm{mol}, 2.1 \times 10^{23} \mathrm{~s}^{-1}\right)$ for other alloys systems except Pd-based metallic glasses.

Furthermore, hypothetical calculations were carried out for $\mathrm{Zr}_{41.2} \mathrm{Ti}_{13.8} \mathrm{Cu}_{12.5} \mathrm{Ni}_{10} \mathrm{Be}_{22.5}$ alloy in order to clarify the influence of $E_{\mathrm{f}}$ and $C_{0}$ on the value of $\Delta T_{\mathrm{x}}$. Figure 9 shows the contour lines of $\Delta T_{\mathrm{x}}$, in $E_{\mathrm{f}}-C_{0}$ diagram under the calculation condition that $B=8444 \mathrm{~K}$ and $T_{0}=372 \mathrm{~K}$, and the representative $\mathrm{dx} / \mathrm{d} T$ profiles. Because no values of $E_{\mathrm{f}}$ and $C_{0}$ are given for the $\mathrm{Zr}_{41.2} \mathrm{Ti}_{13.8} \mathrm{Cu}_{12.5} \mathrm{Ni}_{10} \mathrm{Be}_{22.5}$ alloy, we assume that this alloy has $\left(E_{\mathrm{f}}, C_{0}\right)=\left(160 \mathrm{~kJ} / \mathrm{mol}^{-1}, 2.1 \times 10^{23} \mathrm{~s}^{-1}\right)$. In Fig. 9(a), $\Delta T_{\mathrm{x}}$ was calculated as $11 \mathrm{~K}$ in the sets of $\left(E_{\mathrm{f}}, C_{0}\right)$ values on the line abc, as $22 \mathrm{~K}$ on the line def, and as $44 \mathrm{~K}$ in on the line ghi. Since the calculations were conducted using the condition that $\left(E_{\mathrm{f}}, C_{0}\right)=\left(160 \mathrm{~kJ} / \mathrm{mol}^{-1}, 2.1 \times 10^{23} \mathrm{~s}^{-1}\right)$ for all the alloys in the present study, the calculation results have errors resulting from the fact that we did not use the intrinsic values of $E_{\mathrm{f}}$ and $C_{0}$. The values for $\Delta T_{\mathrm{x}}$ were overestimated by a factor of nearly two in the alloys having $\left(E_{\mathrm{f}}, C_{0}\right)$ plotted in the area between lines abc and def. In contrast, the alloys having $\left(E_{\mathrm{f}}, C_{0}\right)$ plotted in the area between lines ghi and def were underestimated to the same degree. However, in the present study, $\Delta T_{\mathrm{x}}$ was calculated in a range from approximately $5 \mathrm{~K}$ more than $20 \mathrm{~K}$, as shown in Fig. 4(b). This result indicates that the values of $\Delta T_{\mathrm{x}}$, were affected more significantly by the values of $\left(B, T_{0}\right)$ than by those of $\left(E_{\mathrm{f}}, C_{0}\right)$.

Thus, the results shown in Figs. 8 and 9 support the 

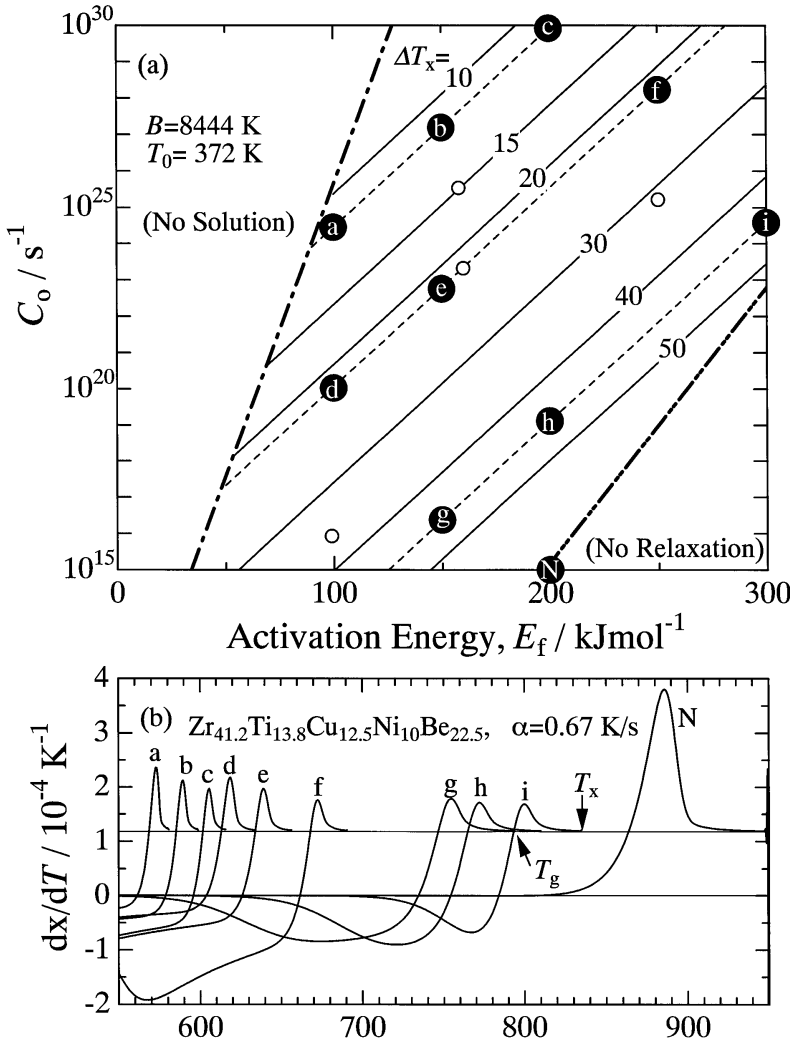

Temperature, $T$ / K

Fig. 9 (a) The contour lines of $\Delta T_{\mathrm{X}}$ in the $E_{\mathrm{f}}-C_{0}$ diagram calculated with the values $B=8444 \mathrm{~K}$ and $T_{0}=372 \mathrm{~K}$. Experimental values of $E_{\mathrm{f}}$ and $C_{0}{ }^{18,22,28)}$ are also shown by open circles. "No relaxation" indicates that no decrease in $\mathrm{x}$ as well as $\mathrm{dx} / \mathrm{d} T$ was calculated before glass transition. (b) $\mathrm{dx} / \mathrm{d} T$ profiles calculated with the $E_{\mathrm{f}}$ and $C_{0}$ denoted in Fig. 9(a).

present calculation condition that $E_{\mathrm{f}}$ and $C_{0}$ can be fixed as $\left(E_{\mathrm{f}}, C_{0}\right)=\left(160 \mathrm{~kJ} / \mathrm{mol}, 2.1 \times 10^{23} \mathrm{~s}^{-1}\right)$.

Thus, the simultaneous lack of the two factors in the present calculation model is presumed to affect the discrepancy between the calculated and experimental $\Delta T_{\mathrm{x}}$ values.

\subsection{The relations between the VFT parameters and $\boldsymbol{R}_{\mathrm{c}}$, $T_{\mathrm{g}} / T_{\mathrm{m}}$ or $\Delta T_{\mathrm{x}}$}

We discuss here the validity of the present calculation model using the VFT parameters for viscosity. In our previous paper, we succeeded in obtaining the theoretical relation corresponding to $R_{\mathrm{c}}$ and $T_{\mathrm{g}} / T_{\mathrm{m}}{ }^{17)}$ from the time-transformation diagram. In this study, the time-transformation diagram was calculated using the VFT parameters and $T_{\mathrm{m}}$ as the minimal necessary parameters. The subsequent analysis was made to clarify the relationship between $R_{\mathrm{c}}$ and $\Delta T_{\mathrm{x}}$ using the VFT parameters. It is significant that the relationship among the GFA factors have been obtained from the VFT equation for viscosity. Figure 10 shows the relationship between the VFT parameters and the GFA factors. It is seen that the viscosity is a key factor to derive all the GFA parameters $\left(R_{\mathrm{c}}, T_{\mathrm{g}} / T_{\mathrm{m}}\right.$ and $\left.\Delta T_{\mathrm{x}}\right)$. From the figure, the minimum necessary parameters for $R_{\mathrm{c}}$ and $T_{\mathrm{g}} / T_{\mathrm{m}}$ are all the VFT parameters $\left(\eta_{0}, B\right.$ and $\left.T_{0}\right)$ and melting temperature $\left(T_{\mathrm{m}}\right)$ whereas that for $\Delta T_{\mathrm{x}}$ is $B$ and $T_{0}$. Figure 10 also shows that the GFA parameters and their relations can be derived from the VFT parameters for viscosity. To the best of our knowledge, these relations are firstly

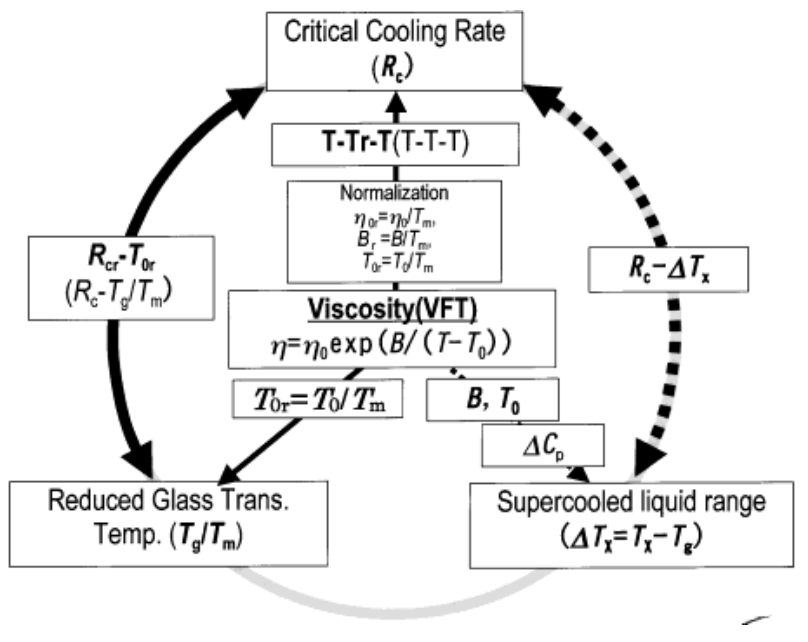

Fig. 10 The relation between the VFT parameters and the GFA factors.

derived from within the framework of this unique model. The viscosity term used in our previous study ${ }^{17)}$ and the present studies is mathematically independent of other terms for the calculation, and hence the other viscosity models can be substitutable for the VFT expression.

\section{Conclusions}

The conclusions derived from the present results and discussion are summarized as follows.

(1) The maximum value of $\Delta T_{\mathrm{x}}$ was calculated as $56 \mathrm{~K}$ for the $\mathrm{SiO}_{2}$ system. The $\log R_{\mathrm{c}}$ tends to decrease linearly with increasing $\Delta T_{\mathrm{x}}$. This tendency is consistent with the experimental result.

(2) The calculated $\Delta T_{\mathrm{X}}$ values for some metallic glasses are approximately six times smaller than the experimental results. The discrepancy between the calculated and experimental $\Delta T_{\mathrm{x}}$ values is due to the lack of the effects of the chemical short range order and the difficulty in the diffusivity for crystallization in the present calculation model.

(3) From the approximate solution of the differential equation, it was clarified that the $T_{\mathrm{g}}$ and $\Delta T_{\mathrm{x}}$ can be derived by the schematic-analysis method in the $\mathrm{x}-T$ diagram.

(4) It is recognized that viscosity is the key factor which affects all the GFA parameters $\left(R_{\mathrm{c}}, T_{\mathrm{g}} / T_{\mathrm{m}}\right.$ and $\left.\Delta T_{\mathrm{x}}\right)$. It was also clarified that the minimum necessary parameters for the calculation of each GFA parameter are all the VFT parameters $\left(\eta_{0}, B\right.$ and $\left.T_{0}\right)$ and melting temperature $\left(T_{\mathrm{m}}\right)$ for $R_{\mathrm{c}}$ and $T_{\mathrm{g}} / T_{\mathrm{m}}$, and $B$ and $T_{0}$ for $\Delta T_{\mathrm{x}}$. It has been shown that the GFA parameters and their relations can be derived from the VFT parameters for viscosity.

\section{REFERENCES}

1) W. Klement, R. H. Willens and P. Duwez: Nature 187 (1960) 869-870.

2) A. Inoue: Bulk Amorphous Alloys-Preparation and Fundamental Characteristics-, Materials Science Foundations 4, (Trans Tech Publications, Netherlands, 1998), pp. 1-116.

3) D. R. Uhlmann: J. Non-Cryst. Solids 7 (1972) 337-348.

4) H. A. Davies: Rapid Quenching and Formation of Metallic Glasses, Rapidly Quenched Metals III, 1, (ed. B. Cantor, The Metal Society, 1978) pp. 1-21.

5) P. M. Anderson, III, J. Steinberg and A. E. Lord, Jr.: J. Non-Cryst. Solids 34 (1979) 267-272. 
6) Y. Nishi, K. Suzuki and T. Masumoto: Proc. 4th Int. Conf. on Rapidly Quenched Metals, (eds. T. Masumoto and K. Suzuki, Japan Inst. Metal., 1982) pp. 217-220.

7) M. C. Weinberg, B. J. Zelinski and D. R. Uhlmann: J. Non-Cryst. Solids 123 (1990) 90-96.

8) A. Jha: Phys. Chem. Glasses 33 (1992) 79-86.

9) N. Clavaguera: J. Non-Cryst. Solids 162 (1993) 40-50.

10) Y. Li: J. Non-Cryst. Solids 175 (1994) 224-227.

11) N. Clavaguera and M. T. Clavaguera-Mora: Mater. Sci. Eng. A179/180 (1994) 288-292.

12) J. A. Diego, M. T. Clavaguera-Mora and N. Clavaguera: Mater. Sci. Eng. A179/180 (1994) 526-530.

13) N. Clavaguera and M. T. Clavaguera-Mora: MRS Symp., Proc. Bulk Metallic Glasses, (eds. W. J. Johnson, A. Inoue and C. T. Liu, MRS 1999554 237-242).

14) A. Takeuchi and A. Inoue: Mater. Sci. Eng. 304-306 (2001) 446-451.

15) Z. P. Lu, H. Tan, Y. Li and S. C. Ng: Scr. Mater 42 (2000) 667-673.

16) Z. P. Lu, H. Tan, Y. Li and S. C. Ng: J. Non-Cryst. Solids 270 (2000) 103-114.

17) A. Takeuchi and A. Inoue: Mater. Trans. 42 (2001) 2374-2381.
18) A. van den Beukel and J. Sietsma: Acta Metall. Mater. 38 (1990) 383389.

19) R. Bush, W. Liu and W. L. Johnson: J. Appl. Phys. 83 (1998) 4134 4141.

20) Y. Li: J. Non-Cryst. Solids 175 (1994) 224-227.

21) Viscosity and Relaxation Glass: Science and Technology vol. 3: (ed. D. R. Uhlmann and N. J. Kreidl, Academic Press 1986) pp. 244-246.

22) J. Zappel and F. Sommer: J. Non-Cryst. Solids 205-207 (1996) 494499.

23) K. Russew, B. J. Zappel and F. Sommer: Scr. Metall. Mater. 32 (1995) 271-276.

24) Metals Reference Book, 5th ed. (eds. C. J. Smithells and E. A. Brandes, Butterworths, 1976) pp. 46.

25) A. van den Beukel, E. Huizer, A. L. Mulder and S. van der Zwaag: Acta Metall. 34 (1986) 493-496.

26) A. van den Beukel: Rapidly Solidified Materials (eds. P. W. Lee and R. S. Carbonara, AMS, Metals Park, Ohio, 1986) pp. 193-203.

27) A. I. Taub and F. Spaepen: Acta Metall. 28 (1980) 1781-1788.

28) G. W. Koebrugge, J. v. d. Stel, J. Sietsuma and A. v. d. Beukel: J. NonCryst. Solids 117/118 (1990) 601-604. 